\title{
Instrumentation
}

\section{A MODIFIED DESIGN FOR THE LYKKEN ZINC ELECTRODES}

As Lykken has so clearly demonstrated, careful choice of skin resistance electrodes is essential for accurate, artifact-free recording (1). The zinc electrodes he describes are of particular interest since they are electrically stable, simple to apply, and require less complicated circuitry than the lead-lead variety. The purpose of this note is to describe a modification of the zinc electrode which has the following advantages: (1) it is simpler to build; described by Lykken. Note, however that the electrodes must be cleaned with water and not with alcohol, since application of alcohol may lead to cracking the lucite body of the electrode. If the electrode is wiped with a tissue immediately after use, even water will rarely be necessary.

\section{Construction}

A 5/16-in. high, $3 / 4$-in. diameter lucite disc forms the body of the elec-
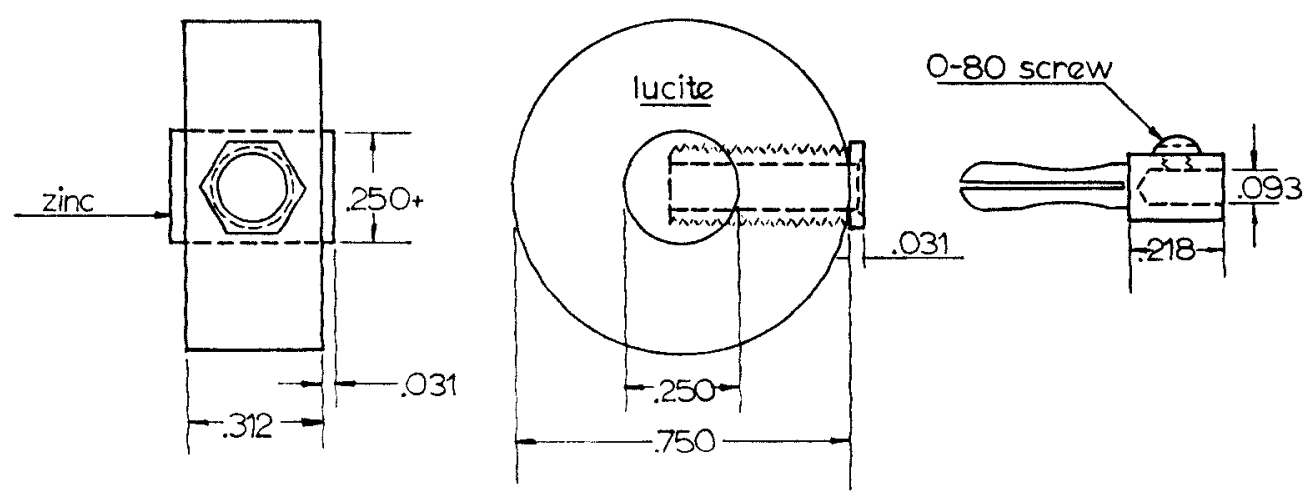

FIG. 1. Construction details for modified Lykken electrode

(2) it lasts longer since it has two usable surfaces; (3) it provides an unusually stable electrical contact; and (4) it permits unplugging the leads from the electrodes, facilitating cleaning and storage of the electrodes. It also allows $S$ temporarily to leave the experimental situation wearing his electrodes without having to contend with dangling leads.

Application procedure and suitable electrode jelly are identical to those

Address request for reprints to Stephen Kaplan, Ph.D., Department of Psychology, University of Michigan, Ann Arbor, Michigan. trode. A 0.250 -in. diameter hole is drilled and reamed axially into the dise, and a 0.392-in. long solid zine cylinder is inserted. This cylinder is $0.2503 \mathrm{in}$. in diameter, affording a hand press fit. It is placed so that it projects equally on both sides of the lucite. With the core in position, a centered radial hole $7 / 16$-in. deep is drilled (No. 20 drill) into the lucite, penetrating the zinc core by roughly $2 / 3$ of its diameter. The hole is then tapped with a bottoming tap, and a banana jack ${ }^{1}$ is screwed in firmly.

${ }^{1}$ Banana jack No. 112 and banana plug. 
The mating plug is made by removing the threaded portion of a banana plug $^{1}$ and drilling an axial hole (No. 54 drill) $3 / 16$-in. deep in the hexagonal part of the plug. This hole accepts the wire from the recorder. To eliminate a soldered joint here, a No. 55 hole is drilled radially $3 / 32$ inch deep in the center of any face of the hex-

No. 111 obtained from Herman H. Smith, Inc., Brooklyn 10, New York. agonal part and is then tapped for a 0-80 screw.

\section{STEPHEN KaPLAN}

G. R. Fisher

Department of Psychology

University of Michigan,

Ann Arbor, Michigan

\section{REFERENCE}

1. Lykken D. T., Properties of electrodes used in electrodermal measurements. $J$. Comp. Physiol. Psychol., 1959, 52, 629. 
This document is a scanned copy of a printed document. No warranty is given about the accuracy of the copy. Users should refer to the original published version of the material. 